\title{
Influence of the mannoproteins of different strains of Starmenella bacillaris used in single and sequential fermentations on foamability, tartaric and protein stabilities of wines
}

Wilson Josè Fernandes Lemos Junior ${ }^{\mathrm{a}} \uparrow$, Chiara Nadai ${ }^{\mathrm{b}, \mathrm{c}} \uparrow$, Luca Rolle ${ }^{\mathrm{d}}$, Eliana da Silva Gulão Maria Helena Miguez da Rocha Leão ${ }^{\mathrm{e}}$, Alessio Giacomini ${ }^{\mathrm{b}, \mathrm{c}}$, Viviana Corich ${ }^{\mathrm{b}, \mathrm{c},},{ }^{*}$, Simone Vincenzi $^{\mathrm{b}, \mathrm{c}}$

aScience and Technology Faculty, Free University of Bozen, 39100, Bolzano, Italy bepartment of Agronomy Food Natural Resources Animals and Environment (DAFNAE), University of Padova, 35020, Legnaro, Italy

'Interdepartmental Centre for Research in Viticulture and Enology (CIRVE), University of Padova, 31015, Conegliano, Italy

dDepartment of Agricultural, Forest and Food Sciences, University of Torino, 10095, Grugliasco, Italy eInstituto de Química, Universidade Federal do Rio de Janeiro (UFRJ), Rio de Janeiro, 21941909, Brazil

$\dagger$ These authors contributed equally to this work.

*Corresponding author: viviana.corich@unipd.it

\section{A B S T R A C T}

Aim: In this work, seven strains of Starmerella bacillaris were analysed for their ability to release polysaccharides during alcoholic fermentation (AF), both in single-strain and in sequential AF together with Saccharomyces cerevisiae.

Methods and results: A synthetic polysaccharide-free must was used to characterise the mannoproteins (MPs) released. The MPs were quantified, characterised in terms of carbohydrate composition, and tested to assess their ability to reduce protein and tartrate instabilities and their ability to affect the foaming properties of wine.

Conclusions: All the tested strains in sequential AF increased the total MPs production. Moreover, the strains affected the MPs properties in different ways regarding tartaric and protein stabilities. The MPs released in sequential AF by some $S$. bacillaris strains showed a significant effect on protein stabilisation and tartaric stability. An effect on the foamability was found for MPs obtained in single-strain AFs of S. bacillaris.

Significance and impact of the study: An improvement in wine stability can be achieved using the sequential AF.

\section{KE Y W O R D S}

polysaccharides, non-Saccharomyces, fermentation, wine quality, mannoproteins 


\section{INTRODUCTION}

Alcoholic fermentation (AF) is one of the most important processes during winemaking and the management of this is key to obtaining a good quality product.

Mannoproteins (MPs) are macromolecules released by yeasts during $\mathrm{AF}$ and during the autolysis of cells in wine ageing on lees (Dupin et al., 2000a; Chalier et al., 2007). The release of MPs depends on yeast strain (González-Ramos et al., 2008), must turbidity (Boivin et al., 1998), temperature (Llaubères et al., 1987), nutritional conditions (sugar, nitrogen) (Ribéreau-Gayon et $a l ., 2006)$ and the chemical composition of the wine $(\mathrm{pH})$. These molecules are glycoproteins with a high sugar content, mainly mannose (Quirós et al., 2010), and are, together with fibrous $\beta-1,3$-glucan, one of the major components of the yeast cell wall, representing an important part of total polysaccharides in wine (Vidal et al., 2003).

In recent years, MPs have become one of the most interesting yeast molecules for the improvement of wine quality, due to their oenological properties such as the enhancement of mouthfeel and the improvement of wine protein and tartaric stabilities (Escot et al., 2001; Moine-Ledoux and Dubourdieu, 2002; Caridi, 2006; González-Ramos et al., 2008; Comuzzo et al., 2011). In 2005, the European Community authorised the addition to wine of MPs obtained from the hydrolysis of yeast cell walls, for improving tartaric and protein stabilisation (EU Regulation 2165/2005).

One of the first oenological properties described for yeast MPs is the partial protection against protein precipitation in white wines. Ledoux et al. (1992) showed that a Sauvignon blanc wine aged on yeast lees has lower haze potential and lower bentonite requirements for stability than wine aged without lees. The compound responsible for improving protein stability in white wine aged on its lees has been identified as a $31.8 \mathrm{kDa}$ mannoprotein (MP32), which was a yeast invertase fragment released from yeast cell walls (Moine-Ledoux and Dubourdieu, 1999).

Waters et al. (1993) isolated from Muscat of Alexandria wine a high molecular weight mannoprotein that is able to prevent visible wine protein haze formation. This molecule, called haze protective factor (HPF), was characterised and a putative structural gene was identified in the Saccharomyces cerevisiae genome (Dupin et al., 2000b).

Another property attributed to MPs is the protection against tartaric instability. MPs inhibit the crystallisation of tartrate salts by lowering the crystallisation temperature (Gerbaud et al., 1996; Moine-Ledoux and Dubourdieu, 2002), preventing thus the occurrence of precipitates in wine. Furthermore, MPs improve the foam of sparkling wines. The hydrophobicity, high glycosylation and high molecular mass of MPs allow them to surround, and thus stabilise, the gas bubbles of the foam. It has been demonstrated that both the production and the stabilisation of foam also depend on other proteins; however, the main contributors to the foam formation are MPs (Coelho et al., 2011; Vincenzi et al., 2014).

Some authors have proposed recombinant $S$. cerevisiae wine yeasts engineered to overproduce MPs (Gonzalez-Ramos and Gonzalez, 2006; Brown et al., 2007; GonzalesRamos et al., 2008). To bypass various countries' regulations on the use of GMOs in food, Quirós et al. (2010) developed a nonrecombinant method to select wine yeasts overproducing MPs, consisting in a random mutagenesis using UV light as a physical agent, followed by a direct selection on YPD (yeast extract-peptone-dextrose medium) plates containing killer toxin from Williopsis saturnus.

To avoid the use of these microorganisms, likely to be viewed as releasing components not normally present in wine, Domizio et al. (2014) proposed the use of non-Saccharomyces wine yeasts, found in grape and winemaking environments, as novel sources of MPs in wine. Giovani et al. (2012) firstly demonstrated that non-Saccharomyces yeasts can release polysaccharides from their cell wall during AF, as with $S$. cerevisiae. They found out that the amount released depends on yeast species and cell vitality. Non-Saccharomyces yeasts, once defined as a spoilage microorganism, predominate in the early stages of must $\mathrm{AF}$ and recently their role has been reconsidered as some were found to enhance the analytical composition and aroma profile of the wine (Jolly et al., 2014; Ciani and Comitini, 2015; Padilla et al., 2016; Vilela, 2019). Several studies proposed the use of controlled mixed fermentations combining the inoculation of nonSaccharomyces yeasts contemporarily or before 
Saccharomyces cerevisiae to improve wine complexity and quality (Ciani and Comitini, 2011; Jolly et al., 2003). Mixed fermentations with Metschnikowia pulcherrima and S. cerevisiae significantly decreased volatile acidity and total acidity of the final wines and showed a positive correlation with mediumchain fatty acids, 2-phenyl ethanol and isoamyl acetate production (Comitini et al. 2011). Mixed and sequential fermentations (first the nonSaccharomyces yeast then $S$. cerevisiae) carried out with Lachancea thermotolerans and an $S$. cerevisiae starter showed a reduction in the volatile acidity and an increase in total acidity, glycerol, 2-phenyl ethanol, ethyl lactate, diacetyl and polysaccharides content (Comitini et al., 2011; Gobbi et al., 2013; Del Fresno et al., 2017). The use of Torulaspora delbrueckii in mixed fermentations with $S$. cerevisiae resulted in an enhancement of the 2-phenyl ethanol and polysaccharides content and a significant reduction in the volatile acidity (Comitini et al. 2011). Other authors found that sequential fermentations with $T$. delbrueckii and $S$. cerevisiae increase the complexity of wine. In fact, the presence of $T$. delbrueckii increased the concentration of some positive esters, such as ethyl lactate or 2-phenylethyl acetate, and of ethyl acetate, diacetyl and isoamyl acetate in wines, keeping volatile acidity and acetaldehyde at suitable levels (Loira et al., 2014; Taillandier et al., 2014; González-Royo et al., 2015; Del Fresno et al., 2017). Moreover, the effect of nonSaccharomyces yeasts on wine foam has been studied, showing that sequential fermentations with $S$. cerevisiae may be a useful tool to improve wine characteristics and quality. Sequential inoculation with $T$. delbrueckii and S. cerevisiae improved wine foamability and foam persistence, while sequential inoculation with $M$. pulcherrima and S. cerevisiae increased both the foam persistence and the smoky and flowery notes in the wine aromatic profile (González-Royo et al., 2015; Medina-Trujillo et al., 2017).

Starmerella bacillaris (synonym Candida zemplinina) is a non-Saccharomyces yeast commonly found in oenological environments (Bovo et al., 2011). Recently, it has shown to be of oenological interest in mixed AF with $S$. cerevisiae, improving the content of compounds related with wine quality. Many studies indicate that the use of $S$. bacillaris, together with $S$. cerevisiae, enhance the glycerol content of wines and cider, with moderate volatile acidity production, and, due to the low ethanol yield, reduce ethanol content (Rantsiou et al., 2012; Bely et al., 2013; Wang et al., 2014; Lemos Junior et al., 2016; Lemos Junior et al., 2017a; Lemos Junior et al., 2017b; Nadai et al., 2018). Moreover, Lemos Junior et al. (2019) proposed the potential use of $S$. bacillaris as a fermentation starter for the production of lowalcohol beverages obtained from unripe grapes.

In this study, seven strains of the nonconventional yeast $S$. bacillaris were investigated for their ability to release MPs during AF in synthetic must, both in singlestrain and in sequential AF together with S. cerevisiae. These molecules were quantified, characterised in terms of carbohydrate composition, and tested to assess their ability to reduce protein and tartrate instabilities and to affect the foaming properties of wine.

\section{MATERIALS AND METHODS}

\section{Yeast strain and fermentation trials in synthetic must}

The yeasts strains used in this work (Table 1) were isolated from fermenting must obtained from dried grape of Raboso Piave variety, as described by Lemos Junior et al. (2016). A loopful of a 3-day-old culture of each yeast strain from a YPD agar plate (yeast extract $10 \mathrm{~g} / \mathrm{L}$, peptone $10 \mathrm{~g} / \mathrm{L}$, dextrose $20 \mathrm{~g} / \mathrm{L}$ ) was used to inoculate $10 \mathrm{~mL}$ of YPD broth in $50 \mathrm{~mL}$ tubes.

A stationary phase culture with approximately $10^{7}-10^{8}$ cells $/ \mathrm{mL}$, determined by optical density (OD) measurements and confirmed by means of plate counts analysis $(\mathrm{CFU} / \mathrm{mL})$, was obtained after $24 \mathrm{~h}$ of incubation at $30^{\circ} \mathrm{C}$. In single-strain $\mathrm{AF}$, the inoculum concentration was $1-1.5 \times 10^{6}$ cells $/ \mathrm{mL}$. The strain $S$. cerevisiae EC1118 (Lallemand Inc., Montreal, Canada) was used as control. In sequential AF the same inoculum size was used for the $S$. bacillaris strain and $S$. cerevisiae EC1118 $\left(1 \times 10^{6}\right.$ cells/ $\mathrm{mL})$. EC1118 was added $48 \mathrm{~h}$ after the inoculum of $S$. bacillaris.

Fermentations were run in synthetic must MS300, prepared as described by Bely et al. (1990), with $100 \mathrm{~g} / \mathrm{L}$ of glucose, $100 \mathrm{~g} / \mathrm{L}$ of fructose and $6 \mathrm{~g} / \mathrm{L}$ of DL-malic acid, $\mathrm{pH} 3.3$. Fermentation trials were performed in triplicate in $120 \mathrm{~mL}$ bottles as described by Bovo et al. (2016). After yeast inoculation, the bottles were 
TABLE 1. Yeast strains used in work.

\begin{tabular}{ccl}
\hline Strain & \multicolumn{1}{c}{ Species } & \multicolumn{1}{c}{ Origin } \\
\hline FRI719 & S. bacillaris & Winery \\
FRI728 & S. bacillaris & Winery \\
FRI729 & S. bacillaris & Winery \\
FRI751 & S. bacillaris & Winery \\
FRI754 & S. bacillaris & Winery \\
FRI779 & S. bacillaris & Winery \\
FRI7100 & S. bacillaris & Winery \\
EC1118 & S. cerevisiae & Industrial strain (Lallemand Inc., \\
\end{tabular}

incubated at $20^{\circ} \mathrm{C} . \mathrm{CO}_{2}$ production was followed by measuring the weight loss of each culture twice a day. All fermentations trials were stopped after $624 \mathrm{~h}$, when the AF of $S$. cerevisiae EC1118 was completed.

\section{Macromolecules isolation}

The fermentation broth was filtered at $0.45 \mu \mathrm{m}$ (cellulose acetate filter) (Sartorius, Goettingen, Germany) and successively ultrafiltered using an Amicon 8400 apparatus (3000 Da cutoff, regenerated cellulose) (Millipore, Burlington, MA) under a constant nitrogen pressure of 3.5 bars. The total macromolecules obtained from the culture filtrates (i.e. mainly MPs) were carefully recovered, dialysed against water using a regenerated cellulose membrane $(3500 \mathrm{Da}$, Fisherbrand) (Millipore, Consett, Durham, UK), then freeze-dried. The obtained powder was weighted and resuspended in water at $10 \mathrm{mg} / \mathrm{mL}$.

\section{Monosaccharide composition}

The hydrolysis of MPs for the determination of the monosaccharide composition was determined according to the method reported by Dai et al. (2010). 4M trifluoroacetic acid $(500 \mu \mathrm{L})$ and water $(300 \mu \mathrm{L})$ were added into the polysaccharide solution $(200 \mu \mathrm{L}, 10 \mathrm{mg} / \mathrm{mL})$ in a vacuum hydrolysis tube (Pierce, Thermo Scientific, Waltham, MA). The tube was sealed under vacuum and kept for $2 \mathrm{~h}$ at $110^{\circ} \mathrm{C}$. After the tube was cooled to room temperature, $800 \mu \mathrm{L}$ of hydrolysate were mixed with $800 \mu \mathrm{L}$ of water and freeze-dried. The residue was resuspended in $200 \mu \mathrm{L}$ of water, filtered and injected in HPLC.

\section{HPLC analysis}

HPLC analysis was performed to determine the concentration of glucose, fructose, mannose, acetic acid, glycerol, and ethanol as described by Nadai et al. (2016): $10 \mu 1$ samples were analysed using a Waters 1525 HPLC binary pump (Waters, Milford, MA) equipped with a $300 \times 7.8 \mathrm{~mm}$ stainless steel column packed with Aminex HPX_87H HPLC column (Bio-Rad, Hercules, CA). A Waters 2414 Refractive Index Detector (Waters, Milford, MA) was used to determine the mannose, glucose, fructose, acetic acid, glycerol, and ethanol. The concentrations, expressed as $\mathrm{g} / \mathrm{L}$, were calculated by using calibration curves of the individual compounds, and peaks area was determined by the Breeze (Waters, Milford, MA) programme.

\section{Tartaric stability of white wine}

The wine tartaric stability was measured using the mini contact test and was carried out by a Tartar Check (Ing. C. Bullio, San Prospero, Italy). The variation of electric conductivity $(\Delta x)$, expressed in $\mu \mathrm{s} / \mathrm{cm}$, indicated the level of stability. Briefly, $20 \mathrm{~mL}$ of wine were brought to $0^{\circ} \mathrm{C}$, then a dose of $300 \mathrm{mg}$ micronised potassium hydrogen tartrate was added (corresponding to a final concentration of $15 \mathrm{~g} / \mathrm{L}$ ) and the conductivity decrease due to tartaric acid precipitation was tracked for $10 \mathrm{~min}$. A very unstable wine (Glera wine from Conegliano area, vintage 2015, pH 3.13, titratable acidity $6.7 \mathrm{~g} / \mathrm{L}$, alcohol content $11.3 \%$, $267 \mu \mathrm{S}$ drop) was used to test the effect of yeast macromolecules, added to the wine at a final concentration of $200 \mathrm{mg} / \mathrm{L}$ before the mini contact test.

\section{Protein stability of white wine}

The protein stability was evaluated by measuring the turbidity of wine after a treatment at $80^{\circ} \mathrm{C}$ for $6 \mathrm{~h}$ followed by $4^{\circ} \mathrm{C}$ for $12 \mathrm{~h}$ (Pocock and Rankine, 1973). The turbidity was measured by the HI83749 Nephelometer (Hanna Instruments, Ronchi di Campanile, Italy) and the difference between the value before and after the treatment was used for calculations. A very unstable wine (Traminer wine, from Tezze sul Brenta, vintage 2015 , pH 3.32, titratable acidity $5.6 \mathrm{~g} / \mathrm{L}$, alcohol content $12.4 \%, 225 \mathrm{NTU}$ after heating) was used to test the effect of yeast macromolecules, added to the wine at a final concentration of $200 \mathrm{mg} / \mathrm{L}$ before the heating. 


\section{Evaluation of foam measurement on white wine}

Foam parameters were measured with a classical Rudin tube $(400 \times 24 \mathrm{~mm}$ i.d.) (Rudin, 1957), closed at the bottom with a sintered glass plate (pore size 40-60 $\mu \mathrm{m}$ ). MPs isolated from the different strains of $S$. bacillaris in single and sequential inoculum were all resuspended at the same concentration $(10 \mathrm{mg} / \mathrm{mL})$ in water and added to a Prosecco base wine at a concentration of $50 \mathrm{mg} / \mathrm{L}$.

Before each analysis, the tube was cleaned with ethanol, and then rinsed three times with deionised water and three times with the sample to be analysed. Then, $50 \mathrm{~mL}$ filtered samples were placed in the tube and $\mathrm{CO}_{2}$ was sparged at a constant flow rate $(110 \mathrm{~mL} / \mathrm{min})$ and pressure $(100 \mathrm{kPa})$ from the bottom. The foam height (FH) was measured every $15 \mathrm{~s}$ for $15 \mathrm{~min}$, the gas flow was stopped, and then the foam decay was monitored. Each sample was analysed in triplicate.

\section{Statistical analysis}

Principal component analysis (PCA) and oneway analysis of variance (ANOVA) at a $95 \%$ accuracy level were performed using XLSTAT software, vers.2016.02 (Addinsoft, Paris, France).

\section{Results and discussion}

\section{MPs release during fermentation}

Fermentation performances of seven strains of $S$. bacillaris, both in single-strain and in sequential AF together with $S$. cerevisiae EC1118, were evaluated in synthetic must. All the fermentations trials were stopped after $624 \mathrm{~h}$, when the AF of $S$. cerevisiae EC1118 was completed. Fermentation vigour, in terms of $\mathrm{CO}_{2}$ production after $48 \mathrm{~h}$ of incubation, $\mathrm{CO}_{2}$ production after $312 \mathrm{~h}$ and when AF was stopped $(624 \mathrm{~h})$, together with sugars consumption and secondary metabolite production, were considered to assess AF performances (Table A.1 and Table A.2). S. bacillaris single-strain fermentation evidenced a high glycerol production and a fermentation rate slower than that of $S$. cerevisiae EC1118. When sequential fermentations were performed in synthetic must the $S$. bacillaris strains significantly increased glycerol content and reduced ethanol concentration, while no significant differences were found in acetic acid concentrations that were comparable to the S. cerevisae EC1118 tested strain.

The AF was conducted in MS300 synthetic must (i.e. without protein or polysaccharide), so every macromolecule present at the end of the AF was exclusively produced and released by yeast cells (Figure 1). S. cerevisiae strain produced a significantly $(\mathrm{p}<0.001)$ higher content of

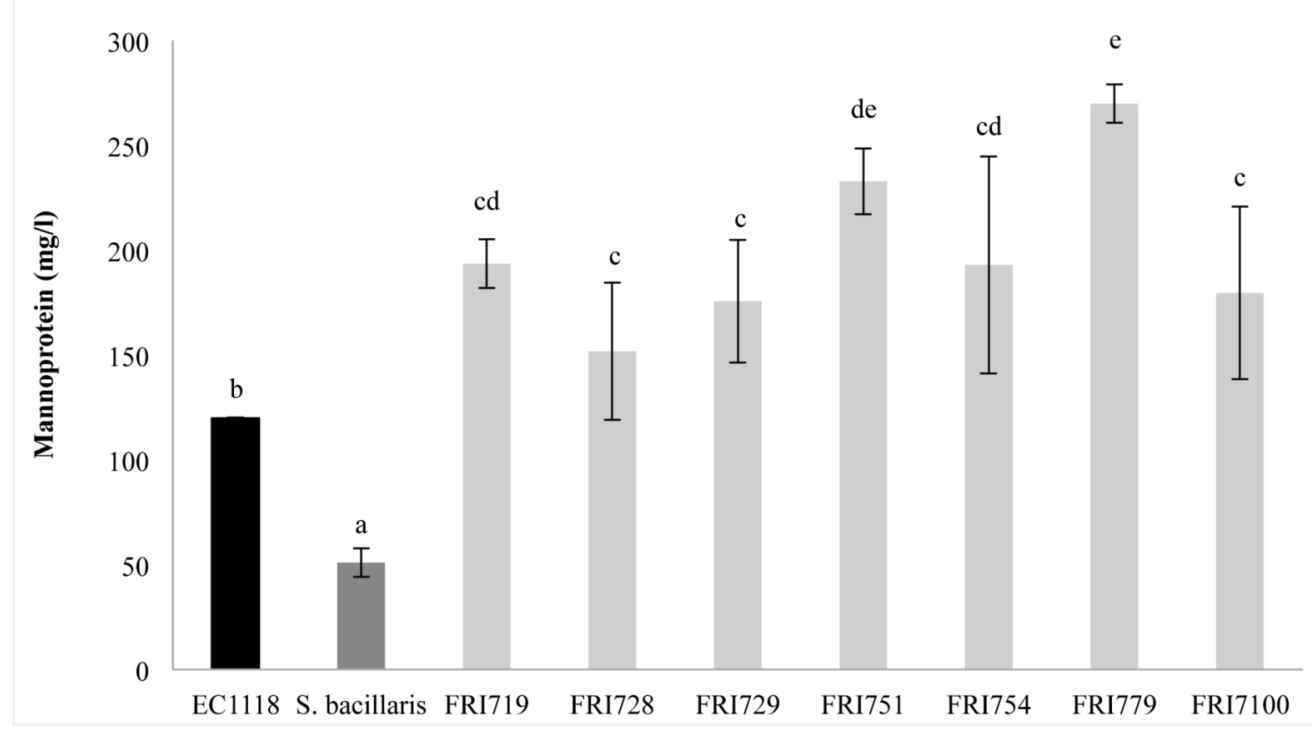

FIGURE 1. Mannoproteins content in S. cerevisiae (EC1118) and S. bacillaris single-strain fermentation (mean of all strains) and sequential fermentation. 


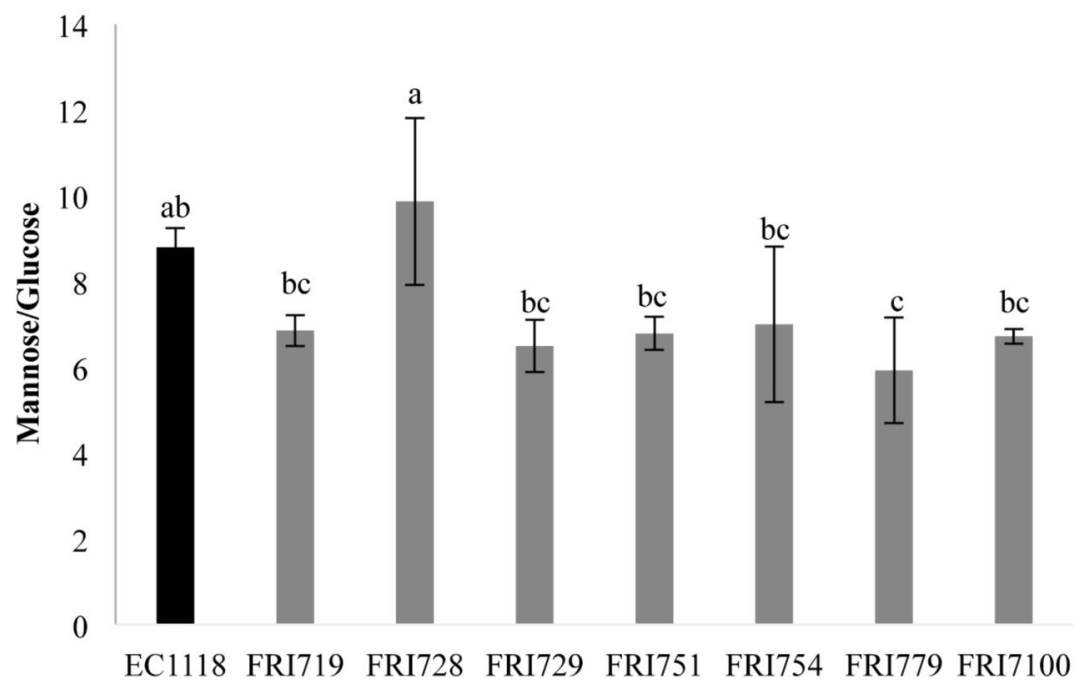

FIGURE 2. The composition with regards to sugars represented by a coefficient (mannose/glucose) of the polysaccharides released by each yeast strain at the end of alcoholic fermentation.

macromolecules $(119 \mathrm{mg} / \mathrm{L})$ than $S$. bacillaris single-strain AFs (from 40.51 to $57.56 \mathrm{mg} / \mathrm{L}$ ).

These results are different from those obtained by Domizio et al. (2014) who found that $S$. bacillaris \#22 released a level of total polysaccharides similar to $S$. cerevisiae EC1118 (around $200 \mathrm{mg} / \mathrm{L}$ ). However, this effect could be explained by the different AF conditions. In fact, Domizio et al. (2014) performed AFs in a "minimal must medium" at $28{ }^{\circ} \mathrm{C}$ under continuous agitation at $150 \mathrm{rpm}$, while in the present study the fermentation conditions are mimicking a must in static fermentation.

The sequential AFs released much higher quantities of macromolecules $(151-270 \mathrm{mg} / \mathrm{L}$ ) than the $S$. cerevisiae single-strain AF $(119 \mathrm{mg} / \mathrm{L})$. This higher macromolecules production in sequential AFs cannot be ascribed solely to the presence of two microorganisms in the same medium, as, in some cases (in particular FRI751 and FRI779), the total macromolecules content is higher than the sum of the macromolecules released by the two microorganisms individually cultured. This behaviour clearly indicates that the interaction existing between the two microorganisms during AF leads to an increase in the macromolecules release into the culture medium. The interaction between different yeasts in multi-starter wine AF has been reviewed by Ciani and Comitini (2015), and has been shown to have an effect on both metabolite production (glycerol, ethanol, esters, etc.) and microbial growth. Regarding cell-wall polysaccharides, even Comitini et al. (2011) found a higher release of polysaccharides by $S$. bacillaris in sequential AF together with $S$. cerevisae than $S$. cerevisiae single-strain AF in natural grape juice. This could be explained by a modulation of $S$. bacillaris death due to the direct interaction with $S$. cerevisiae cells, as recently suggested by Englezos et al. (2019).

\section{Polysaccharides characterisation}

The different macromolecules obtained from the filtered media were suspended in water at $10 \mathrm{mg} / \mathrm{mL}$ and then used for further characterisation.

The analysis of sugar composition confirmed that these polysaccharides released in the media are of cell-wall origin, and therefore essentially MPs. As a matter of fact, only mannose and glucose were found after acidic hydrolysis, with a predominance of mannose, which accounts for about $90 \%$ of the total sugar in the polysaccharides isolated from $S$. cerevisiae (Figure 2). This result is in agreement with data from the literature reporting similar values of mannose content (Escot et al., 2001; Vidal et al., 2003; Domizio et al., 2014). Conversely, the mean content of mannose in MPs isolated from single-strain AFs of $S$. bacillaris is $82.23 \pm 1.43 \%$, according to the data from Domizio et al. (2014). These data confirm the existence of a chemical difference between the MPs released by the two microorganisms, which 
can influence their technological properties, such as the ability to decrease the protein instability in white wines (Ribeiro et al., 2014). Finally, in sequential AFs the mannose percentage of MPs was intermediate (with the exception of sequential AF of FRI728 strain), but still significantly lower (from 85.28 to $87.43 \%$ ) when compared to single-strain AF of EC 1118 (Figure 2).

\section{Tartaric stabilisation}

First, the MPs were added to a very unstable wine at a final concentration of $200 \mathrm{mg} / \mathrm{L}$ to test for their ability to decrease the tartaric instability.

The tendency of tartaric acid to precipitate was determined by measuring the conductivity drop after addition of potassium hydrogen tartrate (crystallisation nuclei) at $0{ }^{\circ} \mathrm{C}$. The effect of MPs on this parameter was measured by comparing the conductivity drop of treated samples with that of untreated wine (Figure 3). On average, the MPs produced by $S$. bacillaris showed low inhibition capacity (from 6.00 to $31.00 \mu \mathrm{S}$ ) when compared with those of EC1118 alone $(41 \mu \mathrm{S})$ $(p<0.001)$. However, the MPs recovered after the sequential AF showed, in some cases (FRI719, FRI751 and FRI779), a significant higher activity compared to single-strain AF of EC1118, indicating a better capacity to inhibit the salt crystallisation. This behaviour confirms an interaction between the two yeast species, as not only the quantity, but also the intrinsic characteristics of MPs were modified when recovered after a sequential AF. We can hypothesise that these MPs modifications could depend on the activity of hydrolytic enzymes released by one or both species able to specifically act on the MPs of the co-fermenting species.

\section{Protein stabilisation}

The MPs were also tested for their ability to affect the protein instability, by adding them to an unstable wine at a final concentration of $200 \mathrm{mg} / \mathrm{L}$. Then the wines were heated at $80{ }^{\circ} \mathrm{C}$ in order to induce the aggregation and precipitation of grape unstable proteins (Pocock and Rankine, 1973).

The induced turbidity was measured by nephelometry and the difference between the initial turbidity and that obtained after heating was noted. The wine used for the experiment was very unstable, giving a value of 225 NTU, and all the results were expressed in comparison to this value. In all cases the addition of MPs caused a reduction of haze risk (Figure 4), confirming the ability of these molecules to decrease the protein precipitation (Waters et al., 1993; Waters et al., 1994).

Considering the MPs released by the S. bacillaris strains when cultured alone, the protective activity (obtained considering the mean value of all the single-strain S. bacillaris) was always significantly higher than the MPs produced by the EC1118 strain $(\mathrm{p}<0.001)$. This

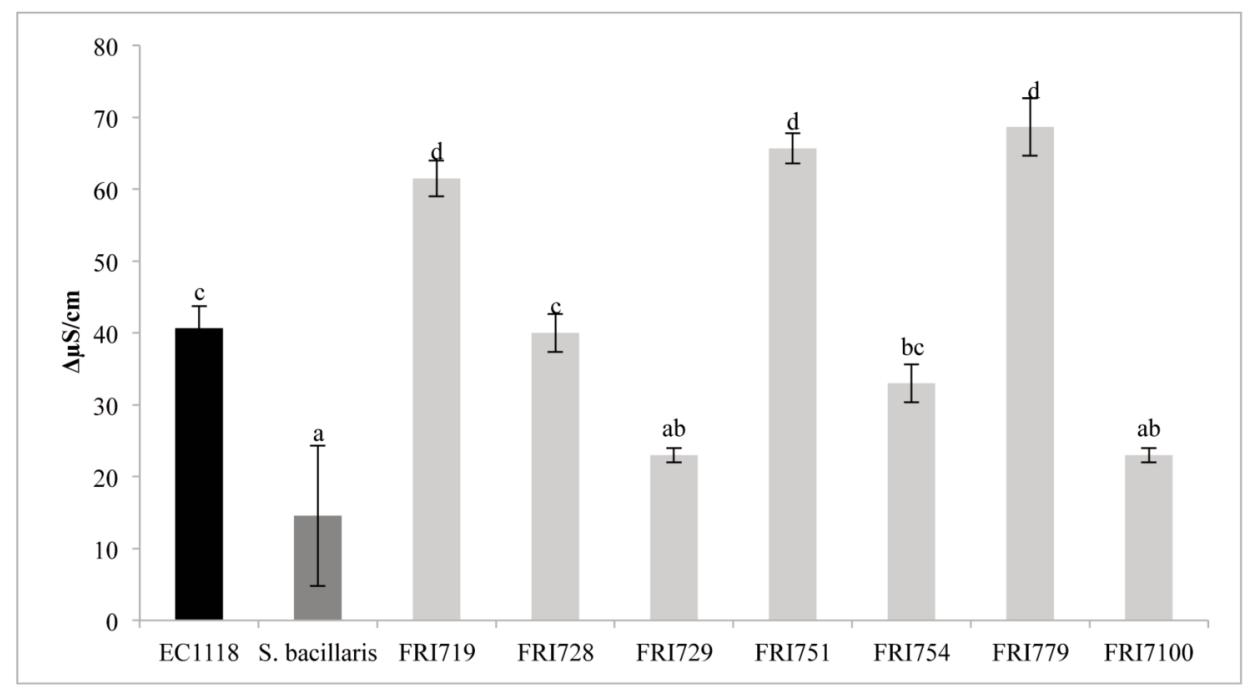

FIGURE 3. Tartaric stabilisation in S. cerevisiae (EC1118) and S. bacillaris single-strain fermentation (mean of all strains) and sequential fermentation. 


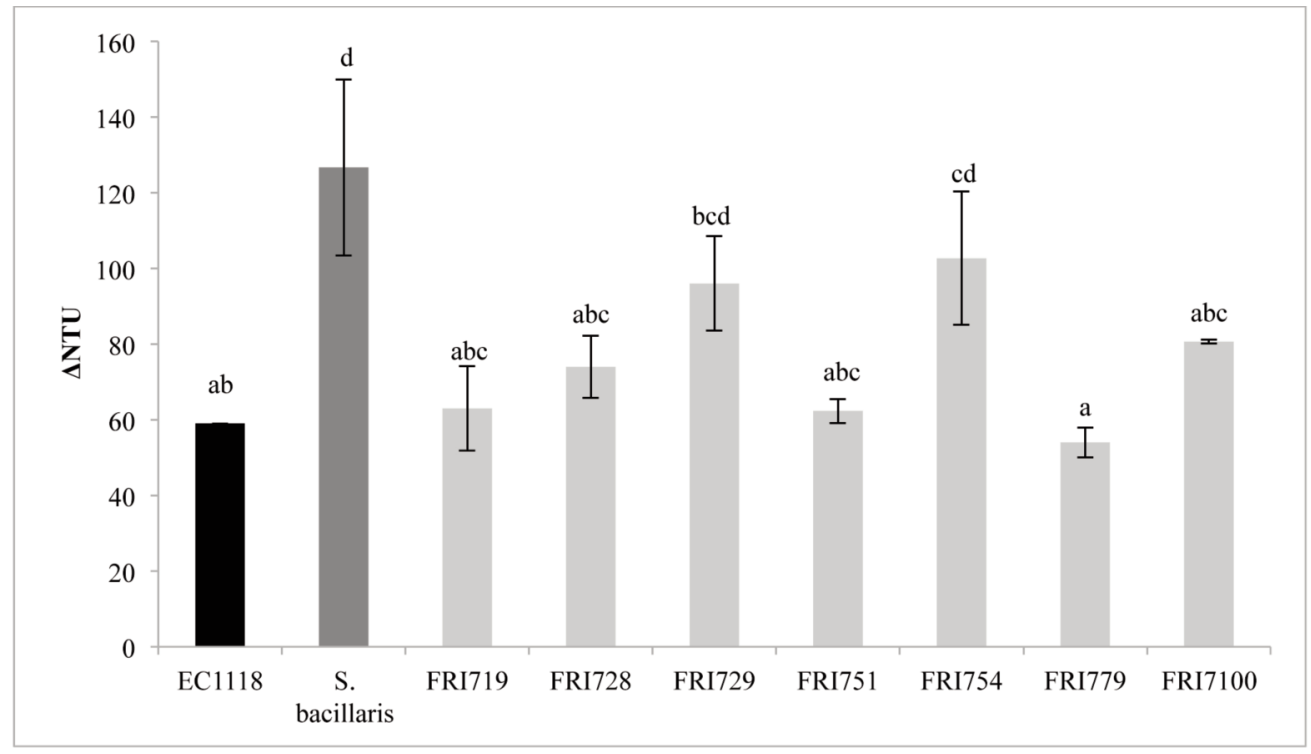

Figure 4. Protein stabilisation in S. cerevisiae (EC1118) and S. bacillaris single-strain fermentation (mean of all strains) and sequential fermentation. The difference in $\triangle$ NTU from the untreated wine (225 NTU) was reported.

is in disagreement with the data reported by Ribeiro et al. (2014), which showed a higher stabilisation effect for MPs with higher mannose to glucose ratio. These data suggest that mannose content is not the only factor affecting the stabilising effect of MPs, and that other factors such as the nature of glycosyl linkages among sugars or the aminoacidic composition of the peptidic fraction could have an important effect on the chemical-physical behaviour of these macromolecules. When the same $S$. bacillaris strains were cultured in sequential inoculum with EC1118, the protein stabilisation effect of the obtained MPs was reduced, but in general, the stabilising effect is comparable to that of the commercial strain alone, and only in one case (FRI754) significantly higher (Figure 4). This strain requires further study, especially in real grape juice, as its use in combination with $S$. cerevisiae should decrease the bentonite demand for protein stabilisation, with wine qualitative improvement, and this could be interesting for winemakers. In addition, the particular stabilising ability of $S$. bacillaris MPs could also be of great interest for the wine products industry, as the most interesting yeast strains could be used for the manufacturing of new oenological products.

\section{Foamability}

The effect on wine foamability of the collected MPs, isolated from Saccharomyces and Starmerella strains in single or in sequential AF, was studied by adding them to a Prosecco base wine.

When added to the wine all at the same concentrations $(50 \mathrm{mg} / \mathrm{L})$, the MPs obtained from Saccharomyces single-AF and sequential AFs increased the foamability (Figure 5), causing an average increase of the maximum height (HM) of about $40 \%$. This is in agreement with the data reported by several studies (Martínez-Rodríguez et al., 2001; Núñez et al., 2006; Vincenzi et al., 2014; González-Royo et al., 2015) which showed that yeast MPs are important for the wine foamability. The foam volumes were significantly higher than that of the original wine (CTRL), but no significant differences were found among the MPs produced by the different strains when cultured in sequential AF, except for strain FRI729. Apparently, the modifications induced by $S$. bacillaris on MPs produced and released in sequential AF did not influence their effect on wine foamability, at least at the tested concentration $(50 \mathrm{mg} / \mathrm{L})$. Therefore, it could be hypothesised that the MPs released by $S$. cerevisiae in the presence or absence of Starmerella have a similar effect in terms of 


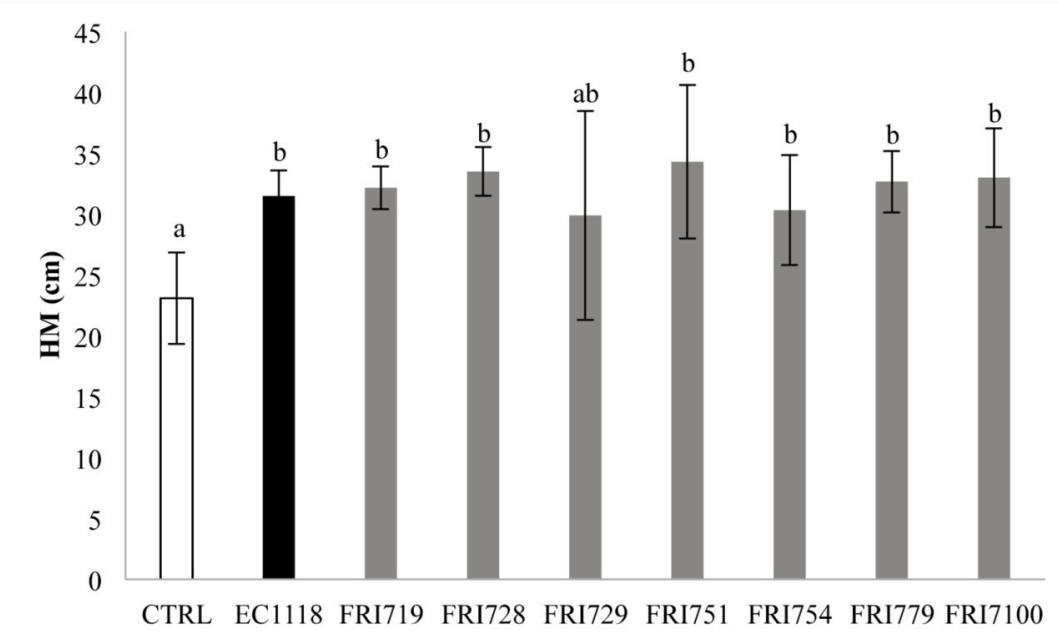

FIGURE 5. Maximum foam height (HM) obtained after the addition of $50 \mathrm{mg} / \mathrm{L}$ of mannoproteins isolated from single-strain fermentations of Saccharomyces and from sequential fermentations with the seven strains of Starmerella bacillaris. Samples with different letters are statistically different $(\mathrm{p}=0.05)$.

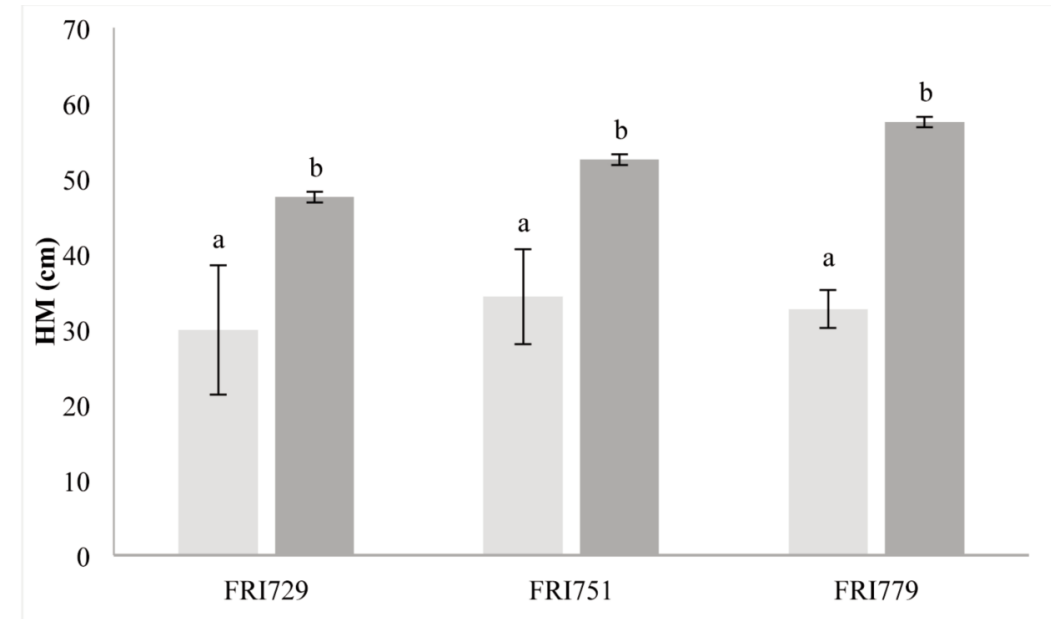

FIGURE 6. Maximum foam height (HM) obtained after the addition of $50 \mathrm{mg} / \mathrm{L}$ of mannoproteins isolated from different strains of Starmerella bacillaris in single-strain ( $\square$ ) and sequential ( $\square$ ) fermentation. For each strain, samples with different letters are statistically different $(p<0.05)$.

wine foamability, and that the effect of the different strains of Starmerella is reflected in the quantity of released MPs. However, different concentrations of MPs, such as $100 \mathrm{mg} / \mathrm{L}, 200$ $\mathrm{mg} / \mathrm{L}$ or more, must be tested to verify the effect on wine foamability.

However, among the MPs produced in singlestrain AF by Starmerella bacillaris, three (FRI729, FRI751 and FRI779) showed a much higher foaming capacity compared to those produced by the same strains in sequential AFs (Figure 6). This is clearly linked to a different composition of the MPs produced by Starmerella in single-strain AF in respect to those produced in sequential AF with $S$. cerevisiae, as reported above.

A PCA analysis on all the collected data (MPs release, FH (HM), tartaric and protein stabilisation) for single-strain and sequential AFs (Figure 7) showed that two main factors (F1 and F2) account for $97.40 \%$ of total variance, with F1 and F2 accounting for $76.31 \%$ and $21.09 \%$, respectively. The analysis confirmed the high level of differences between MPs of the single-strain $\mathrm{AF}$ of $S$. bacillaris, grouped on the right side of the graphic, and that of EC1118 (both in single-strain and in sequential AF), grouped on the left side. 


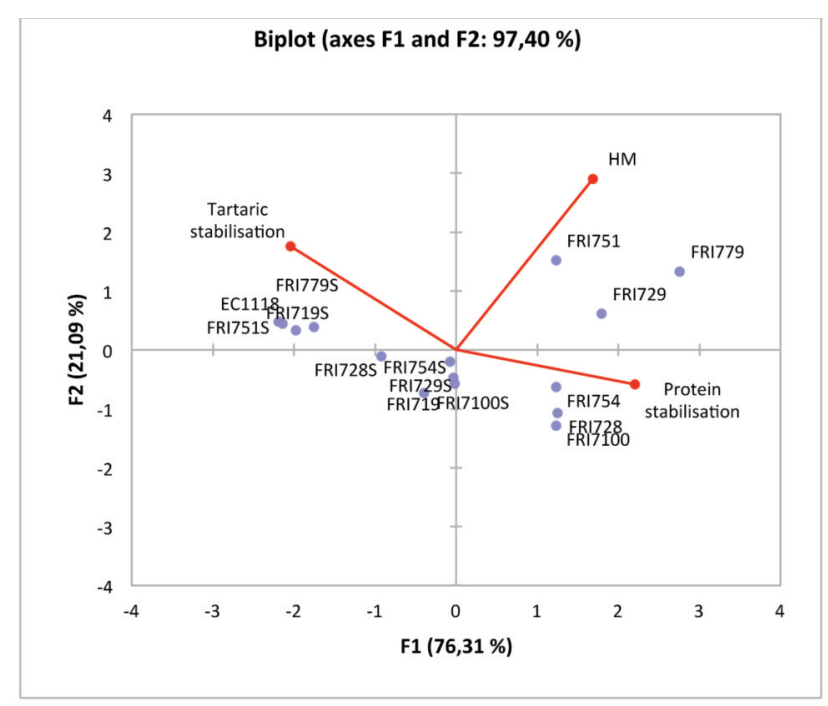

FIGURE 7. Principal component analysis (PCA) biplot showing fermentation performances (variables: mannoprotein production, foam height (HM), tartaric and protein stabilisation) of single-strain fermentations of $S$. bacillaris strains (observations from FRI719 to FRI7100) and strain EC1118 (observation EC1118) and of sequential fermentation of S. bacillaris strains together with EC1118 (observations from FRI719S to FRI7100S) in MS300. Only variables that showed significant correlations are reported.

It is interesting to note that the ability to decrease the tartaric instability in general does not coexist with the ability to improve the protein stability, in fact the two vectors are opposite, with a correlation coefficient of -0.887 . This behaviour confirms that the tartaric and protein stabilisation are based on different mechanisms and, consequently, differently affected by the MPs structure.

The foaming properties of these MPs (HM), on the contrary, are not correlated to the other two parameters.

\section{CONCLUSIONS}

Even though they are not able to complete the AF, $S$. bacillaris strains can be used in sequential AF with $S$. cerevisae to improve some organoleptic properties. In addition, the data here reported demonstrate that the interaction between the two microorganisms affect differently the MPs production in terms of both quantity and quality. All the tested strains in sequential AF increased the total MPs production, but the strains affected in different ways the MPs properties in terms of tartaric and protein stabilities. This is interesting from the technological point of view, as it suggests a possibility to use different selected strains to obtain specific characteristics. It will be interesting to check the results in a real grape juice, as there may be differences in respect to synthetic must. In fact, a direct relationship between the degree of grape must clarification and the quantity of yeast macromolecules recovered in the wine has been described (Guilloux-Benatier et al., 1995). Furthermore, Boivin et al. (1998) reported that yeast cell-wall porosity increased in clarified must, but that macromolecule production decreased. The most interesting aspect is that the improvement in stability can be achieved during the AF, reducing the extent of stabilising treatments at the end of winemaking process. This is converted in a greater sustainability as it leads to a reduction of costs and environmental pollution and in an improvement of organoleptic properties (i.e. a reduction of aroma loss associated with bentonite fining).

In addition, the particular ability of MPs released in single-strain AF by some $S$. bacillaris strains (i.e. a high effect on protein stabilisation or on foam volume) could be interesting as a source for the manufacturing of new oenological products.

Further studies in natural grape juice, aimed to verify the $S$. bacillaris MPs properties discovered in synthetic must, are needed, because in the latter medium yeasts could over- 
release mannoproteins in comparison with fermentations in grape must.

Acknowledgements: The authors wish to thank CAPES - Coordenação de Aperfeiçoamento de Pessoal de Nível Superior.

\section{REFERENCES}

Bely M., Sablayrolles J.M. and Barre P., 1990. Description of alcoholic fermentation kinetics: its variability and significance. American Journal of Enology and Viticulture 41(4), 319-324.

Bely M., Renault P., da Silva T., MasneufPomarède I., Warren A., Moine V., Coulon J., Sicard D., de Vienne D. and Marullo P., 2013. Alcohol level reduction in wine. In P.L. Teissedre (Ed.), Non-conventional yeasts and alcohol level reduction. Bordeaux: Vigne et Vin Publications Internationales, pp. 33-37.

Boivin S., Feuillat M., Alexandre H. and Charpentier C., 1998. Effect of must turbidity on cell wall porosity and macromolecule excretion of Saccharomyces cerevisiae cultivated on grape juice. American Journal of Enology and Viticulture 49(3), 325-332.

Bovo B., Giacomini A. and Corich V., 2011. Effects of grape marcs acidification treatment on the evolution of indigenous yeast populations during the production of grappa. Journal of Applied Microbiology 111, 382-388. doi:10.1111/j.13652672.2011.05060.x

Bovo B., Nadai C., Vendramini C., Fernandes Lemos Junior W.J., Carlot M., Skelin A., Giacomini A. and Corich V., 2016. Aptitude of Saccharomyces yeasts to ferment unripe grapes harvested during cluster thinning for reducing alcohol content of wine. International Journal of Food Microbiology 236, 56-64. doi:10.1016/j.ijfoodmicro.2016.07.022

Brown S.L., Stockdale V.J., Pettolino F., Pocock K.F., de Barros Lopes M., Williams P.J., Bacic A., Fincher G.B., Høj P.B. and Waters E.J., 2007. Reducing haziness in white wine by overexpression of Saccharomyces cerevisiae genes YOL155c and YDR055w. Applied Microbiology and Biotechnology 73(6), 1363. doi:10.1007/s00253-0060606-0

Caridi A., 2006. Enological functions of parietal yeast mannoproteins. Antonie van Leeuwenhoek 89, 417-422. doi:10.1007/s10482-005-9050-x

Chalier P., Angot B., Delteil D., Doco T. and Gunata Z., 2007. Interactions between aroma compounds and whole mannoprotein isolated from Saccharomyces cerevisiae strains. Food Chemistry 100(1), 22-30. doi:10.1016/j.foodchem.2005.09.004

Ciani M. and Comitini F., 2011. Non-Saccharomyces wine yeasts have a promising role in biotechnological approaches to winemaking. Annals of Microbiology 61, 25-32. doi: 10.1007/s13213-010-0069-5

Ciani M. and Comitini F., 2015. Yeast interactions in multi-starter wine fermentation. Current Opinion in Food Science 1, 1-6. doi:10.1016/j.cofs.2014.07.001

Coelho E., Rocha, S.M. and Coimbra M.A., 2011. Foamability and foam stability of molecular reconstituted model sparkling wines. Journal of Agricultural and Food Chemistry 59(16), 8770-8778. doi:10.1021/jf2010657

Comitini F., Gobbi M., Domizio P., Romani C., Lencioni L., Mannazzu I. and Ciani M., 2011. Selected non-Saccharomyces wine yeasts in controlled multistarter fermentations with Saccharomyces cerevisiae. Food Microbiology 28(5), 873-882. http://doi.org/10.1016/j.fm.2010.12.001

Comuzzo P., Tat L., Fenzi D., Brotto L., Battistutta F. and Zironi P., 2011. Interactions between yeast autolysates and volatile compounds in wine and model solution. Food Chemistry 127(2), 473-480. ttps://doi.org/10.1016/j.foodchem.2011.01.026

Dai J., Wu Y., Chen S.W., Zhu S., Yin H.P., Wang M. and Tang J., 2010. Sugar compositional determination of polysaccharides from Dunaliella salina by modified RP-HPLC method of precolumn derivatization with 1-phenyl-3-methyl-5-pyrazolone. Carbohydrate Polymers 82(3), 629-635. doi:10.1016/j.carbpol.2010.05.029

Del Fresno J.M., Morata A., Loira I., Bañuelos M.A., Escott C., Benito S., González Chamorro C. and Suárez-Lepe J.A., 2017. Use of non-Saccharomyces in single-culture, mixed and sequential fermentation to improve red wine quality. European Food Research and Technology 243(12), 2175-2185. doi: 10.1007/s00217-017-2920-4

Domizio P., Liu, Y., Bisson L.F. and Barile D., 2014. Use of non-Saccharomyces wine yeasts as novel sources of mannoproteins in wine. Food Microbiology 43, 5-15. doi: 10.1016/j.fm.2014. 04.005

Dupin I.V., McKinnon B.M., Ryan C., Boulay M., Markides A.J., Jones G.P., Williams P.J. and Waters E.J., 2000a. Saccharomyces cerevisiae mannoproteins that protect wine from protein haze: their release during fermentation and lees contact and a proposal for their mechanism of action. Journal of Agricultural and Food Chemistry 48(8), 3098-3105. doi: $10.1021 / \mathrm{jf} 0002443$

Dupin I.V., Stockdale V.J., Williams P.J., Jones G.P., Markides A.J. and Waters E.J., 2000b. Saccharomyces cerevisiae mannoproteins that protect wine from protein haze: evaluation of extraction methods and immunolocalization. Journal of Agricultural and Food Chemistry 48(4), 1086-1095. doi:10.1021/ jf9905020

Englezos V., Rantsiou K., Giacosa S., Segade S.R., Rolle L. and Cocolin L., 2019. Cell-to-cell contact 
mechanism modulates Starmerella bacillaris death in mixed culture fermentations with Saccharomyces cerevisiae. International Journal of Food Microbiology 289, 106-114. doi:10.1016/j.ijfood micro.2018.09.009

Escot S., Feuillat M., Dulau L. and Charpentier C., 2001. Release of polysaccharides by yeasts and the influence of released polysaccharides on colour stability and wine astringency. Australian Journal of Grape and Wine Research 7(3), 153-159.

Gerbaud V., Gabas, N., Laguerie C., Blouin J., Vidal S., Moutounet M. and Pellerin P., 1996. Effect of wine polysaccharides on the nucleation of potassium hydrogen tartrate in model solutions. Chemical Engineering Research and Design 74(7), 782-790.

Giovani G., Rosi I. and Bertuccioli M., 2012. Quantification and characterization of cell wall polysaccharides released by non-Saccharomyces yeast strains during alcoholic fermentation. International Journal of Food Microbiology 160(2), 113-118. doi: 10.1016/j.ijfoodmicro.2012.10.007.

Gobbi M., Comitini F., Domizio P., Romani C., Lencioni L., Mannazzu I. and Ciani M., 2013. Lachancea thermotolerans and Saccharomyces cerevisiae in simultaneous and sequential cofermentation: a strategy to enhance acidity and improve the overall quality of wine. Food Microbiology 33(2), 271-281. doi:10.1016/j.fm. 2012.10.004

Gonzalez-Ramos D. and Gonzalez P., 2006. Genetic determinants of the release of mannoproteins of enological interest by Saccharomyces cerevisiae. Journal of Agricultural and Food Chemistry 54(25), 9411-9416. doi:10.1021/jf062196d

Gonzales-Ramos D., Cebollero E. and Gonzalez P., 2008. A recombinant Saccharomyces cerevisiae strain overproducing mannoproteins stabilizes wine against protein haze. Applied and Environmental Microbiology 74(17), 5533-5540. doi: 10.1128/AEM .00302-08.

González-Royo, E., Pascual, O., Kontoudakis, N., Esteruelas M., Esteve-Zarzoso B., Mas A., Canals J.M. and Zamora F., 2015. Oenological consequences of sequential inoculation with nonSaccharomyces yeasts (Torulaspora delbrueckii or Metschnikowia pulcherrima) and Saccharomyces cerevisiae in base wine for sparkling wine production. European Food Research and Technology 240(5), 999-1012. doi:10.1007/s00217 -014-2404-8

Guilloux-Benatier M., Guerreau J. and Feuillat M., 1995. Influence of initial colloid content on yeast macromolecule production and on the metabolism of wine microorganisms. American Journal of Enology and Viticulture 46(4), 486-492.
Jolly N.P., Augustyn O.P.H. and Pretorius I.S., 2003. The use of Candida pulcherrima in combination with Saccharomyces cerevisiae for the production of Chenin blanc wine. South African Journal of Enology and Viticulture 24(2), 63-69. doi:10.21548/24-2-2641

Jolly N.P., Varela C. and Pretorius I.S., 2014. Not your ordinary yeast: non-Saccharomyces yeasts in wine production uncovered. FEMS Yeast Research 14(2), 215-237. doi:10.1111/1567-1364.12111

Ledoux V., Dulau L. and Dubourdieu D., 1992. Interprétation de l'amélioration de la stabilité protéique des vins au cours de l'élevage sur lies. $J$. Int. Sci. Vigne Vin 26(4), 239-251. doi:10.20870 /oeno-one.1992.26.4.1188

Lemos Junior W.J., Bovo B., Nadai C., Crosato G., Carlot M., Favaron F., Giacomini A. and Corich V., 2016. Biocontrol ability and action mechanism of Starmerella bacillaris (synonym Candida zemplinina) isolated from wine musts against gray mold disease agent Botrytis cinerea on grape and their effects on alcoholic fermentation. Frontiers in Microbiology 7, 1249. doi: 10.3389/fmicb.2016. 01249.

Lemos Junior W.J.F., Treu L., Duarte V.D.S., Campanaro S., Nadai C., Giacomini A. and Corich V., 2017a. Draft Genome Sequence of the Yeast Starmerella bacillaris (syn. Candida zemplinina) FRI751 Isolated from Fermenting Must of Dried Raboso Grapes. Genome Announcements 5(17), pii: e00224-17. doi: 10.1128/genome A.00224-17.

Lemos Junior W.J.F., Treu L., da Silva, Duarte V., Carlot M., Nadai C., Campanaro S., Giacomini A. and Corich V., 2017b. Whole-Genome Sequence of Starmerella bacillaris PAS13, a Non conventional Enological Yeast with Antifungal Activity. Genome Announcements 5(32), pii: e00788-17. doi: 10.1128/genomeA.00788-17.

Lemos Junior W.J.F., Nadai C., Crepalde L.T., de Oliveira V.S., de Matos A. D., Giacomini A. and Corich V., 2019. Potential use of Starmerella bacillaris as fermentation starter for the production of low-alcohol beverages obtained from unripe grapes. International Journal of Food Microbiology 303, 1-8. doi: 10.1016/j.ijfoodmicro.2019.05.006.

Llaubères P.M., Dubourdieu D. and Villettaz J.C., 1987. Exocellular polysaccharides from Saccharomyces in wine. Journal of the Science of Food and Agriculture 41(3), 277-286. doi:10.1002/ jsfa.27404 10310.

Loira I., Vejarano P., Bañuelos M.A., Morata A., Tesfaye W., Uthurry C., Villa A., Cintora I. and Suárez-Lepe J.A., 2014. Influence of sequential fermentation with Torulaspora delbrueckii and Saccharomyces cerevisiae on wine quality. LWTFood Science and Technology 59(2), 915-922. doi:10.1016/j.lwt.2014.06.019 
Martínez-Rodríguez A., Carrascosa A.V., Barcenilla J.M., Pozo-Bayón M.A. and Polo M.C., 2001. Autolytic capacity and foam analysis as additional criteria for the selection of yeast strains for sparkling wine production. Food Microbiology 18(2), 183-191. doi:10.1006/fmic.2000.0390

Medina-Trujillo L., González-Royo E., Sieczkowski N., Heras J., Canals J.M. and Zamora F., 2017. Effect of sequential inoculation (Torulaspora delbrueckii/Saccharomyces cerevisiae) in the first fermentation on the foaming properties of sparkling wine. European Food Research and Technology 243(4), 681-688. doi:10.1007/s00217-016-2781-2

Moine-Ledoux V. and Dubourdieu D., 1999. An invertase fragment responsible for improving the protein stability of dry white wines. Journal of the Science of Food and Agriculture 79(4), 537-543. http://doi.org/10.1002/(SICI)1097-0010(19990315)7 9:4<537::AID-JSFA214>3.0.CO;2-B

Moine-Ledoux V. and Dubourdieu D., 2002. Rôle des mannoprotéines de levures vis-à-vis de la stabilisation tartrique des vins. Bulletin de l'OIV 75(857-58), 471-482.

Nadai C., Treu L., Campanaro S., Giacomini A. and Corich V., 2016. Different mechanisms of resistance modulate sulfite tolerance in wine yeasts. Applied Microbiology and Biotechnology 100(2), 797-813. doi:10.1007/s00253-015-7169-x

Nadai C., Junior W. J.F.L., Favaron F., Giacomini A. and Corich V., 2018. Biocontrol activity of Starmerella bacillaris yeast against blue mold disease on apple fruit and its effect on cider fermentation. PloS One 13(9), e0204350. doi:10.1371/journal. pone. 0204350

Núñez Y.P., Carrascosa A.V., González P., Polo M.C. and Martínez-Rodríguez A., 2006. Isolation and characterization of a thermally extracted yeast cell wall fraction potentially useful for improving the foaming properties of sparkling wines. Journal of Agricultural and Food Chemistry 54(20), 7898-7903. doi:10.1021/jf0615496

Padilla B., Gil J.V. and Manzanares P., 2016. Past and future of non-Saccharomyces yeasts: from spoilage microorganisms to biotechnological tools for improving wine aroma complexity. Frontiers in Microbiology 7, 411. doi: 10.3389/fmicb.2016.00411.

Pocock K.F. and Rankine B.C., 1973. Heat test for detecting protein instability in wine. Australian Wine, Brewing and Spirit Review 91(5), 42-43.

Quirós M., Gonzalez-Ramos D., Tabera L. and Gonzalez P., 2010. A new methodology to obtain wine yeast strains overproducing mannoproteins. International Journal of Food Microbiology 139(1), 9-14. doi: 10.1016/j.ijfoodmicro.2010.02.014.

Rantsiou K., Dolci P., Giacosa S., Torchio F., Tofalo P., Torriani S., Suzzi G., Rolle L. and Cocolin L., 2012. Candida zemplinina can reduce acetic acid produced by Saccharomyces cerevisiae in sweet wine fermentations. Applied and Environmental Microbiology 78(6), 1987-1994. doi:10.1128/AEM. 06768-11.

Ribeiro T., Fernandes C., Nunes F.M., FilipeRibeiro L. and Cosme F., 2014. Influence of the structural features of commercial mannoproteins in white wine protein stabilization and chemical and sensory properties. Food Chemistry 159, 47-54. doi:10.1016/ j.foodchem.2014.02.149

Ribéreau-Gayon P., Dubourdieu D., Donèche B. and Lonvaud A., 2006. Handbook of enology: The microbiology of wine and vinifications. Chichester: Wiley and Sons Ltd., Vol. 1). doi:10.1002/04700 10363

Rudin A.D., 1957. Measurement of the foam stability of beers. Journal of Institute of Brewing 63, 506e509. doi:10.1002/j.2050-0416.1957.tb06291.x

Taillandier P., Lai Q.P., Julien-Ortiz A. and Brandam C., 2014. Interactions between Torulaspora delbrueckii and Saccharomyces cerevisiae in wine fermentation: influence of inoculation and nitrogen content. World Journal of Microbiology and Biotechnology 30(7), 1959-1967. doi:10.1007/ s11274-014-1618-z

Vidal S., Williams P., Doco T., Moutounet M. and Pellerin P., 2003. The polysaccharides of red wine: total fractionation and characterization. Carbohydrate Polymers 54(4), 439-447. doi:10.1016/S0144 -8617(03)00152-8.

Vilela A., 2019. Use of nonconventional yeasts for modulating wine acidity. Fermentation 5(1), 27. doi:10.3390/fermentation5010027

Vincenzi S., Crapisi A. and Curioni A., 2014. Foamability of Prosecco wine: cooperative effects of high molecular weight glycocompounds and wine PR-proteins. Food Hydrocolloids 34, 202-207. doi:10.1016/j.foodhyd.2012.09.016

Wang C., Esteve-Zarzoso B. and Mas A., 2014. Monitoring of Saccharomyces cerevisiae, Hanseniaspora uvarum, and Starmerella bacillaris (synonym Candida zemplinina). populations during alcoholic fermentation by fluorescence in situ hybridization. International Journal of Food Microbiology 191, 1-9. doi: 10.1016/j.ijfoodmicro. 2014.08.014.

Waters E.J., Wallace, W., Tate M.E. and Williams P.J., 1993. Isolation and partial characterization of a natural haze protective factor from wine. Journal of Agricultural and Food Chemistry 41(5), 724-730. doi:10.1021/jf00029a009

Waters E.J., Pellerin P. and Brillouet J.M., 1994. A Saccharomyces mannoprotein that protects wine from protein haze. Carbohydrate Polymers 23(3), 185-191. doi:10.1016/0144-8617(94)90101-5 